\title{
Local irrigation systems, regional hydrological problems and the demand for overarching solutions at the example of an irrigation system in the P.R. of China
}

\author{
David Nijssen $^{1}$, Andreas H. Schumann ${ }^{2}$, and Bertram Monninkhoff ${ }^{3}$ \\ ${ }^{1}$ Federal Institute of Hydrology, 56002 Koblenz, Germany \\ ${ }^{2}$ Ruhr-University, 44801 Bochum, Germany \\ ${ }^{3}$ DHI-WASY GmbH, 12489 Berlin, Germany \\ Correspondence to: David Nijssen (nijssen@bafg.de)
}

Published: 12 May 2016

\begin{abstract}
The utilization of groundwater for irrigation purposes becomes problematic if groundwater recharge decreases through climate variability. Nevertheless, the degree of groundwater utilization for irrigation increases significantly in dry periods, when the amount of green water is strongly limited. With an increasing gap between water demand and supply, new water management activities are started, which are mostly directed to increase the supply, often by overuse of local resources. In many cases such local activities results in their summarization in side-effects, which worsen the hydrological conditions throughout a region. Step by step the spatial scale of water management measures has to be extended in such cases by implementation of water transfer systems. In this contribution this general scale problem of water management is discussed at the example of an agricultural region in the Province of Shandong (P.R. of China). The local irrigation systems and the options to increase the water supply at the local scale (e.g. by waste water reuse) are discussed as well as regional measures e.g. reservoirs or barrages in rivers to increase the groundwater recharge. For this purpose, several socio-economic and hydrological models were combined. It is shown how a change of water policy towards a demand management requires a new approach to spatial aspects. Here the question arises, how hydrological most effective measures can be allocated within a region. In the case study, a reduction of agricultural irrigation and a change of the crop structure would be essential to improve the groundwater conditions, which are impaired by ongoing sea-water intrusions. A model hierarchy, which is needed to answer such problems not only from the hydrological point of view, but also considering their socio-economic feasibility, are presented.
\end{abstract}

\section{Introduction}

Water resources management can be implemented on a wide range of legal, socio-economic and technical-geographical levels. The large variety of possible measures and their direct and indirect implications poses specific problems concerning their comparison. Often the solution of importing water from neighbouring regions and even over long distances seems to be a "deus ex machina" to solve local and regional water problems that had previously seemed impossible to solve. The question arises if regional water problems are really unsolvable or if the conditions to solve them are only too complex to determine a feasible solution. Like the sources of water supply, the different aspects of water demand have to be analyzed in a holistic way. To objectively compare water management measures to each other, their effects have to be commensurable. Therefore, comparing benefits of water utilizations across sectors should only be performed as an initial and very rough orientation aid and not as a final decision instrument as for instance in Addams et al. (2009). Cubic meters of saved water across sectors are not commensurable: their possible merits vary from a localized few hundred cubic meters reduction in irrigation water losses (Brouwer, 2005; Bjornlund, 2009) over city-wide thousands cubic meters of rainwater collection (Patel and Sah, 2008), to inter basin water transfers of millions of cubic meters of water (Ghassemi 
and White, 2007; Cai, 2008); from replacing water faucets in households (Governing Board of the National Research Council, 2005; National Development and Reform Commission, 2005) over province-wide crop changes (Bishop et al., 2010) to high-tech nuclear desalination plants (El-Dessouky and Ettouney, 2002; Wang et al., 2003). To compare these measures and their variations in implementation extent with each other according to their effect on the specific local hydrological conditions, a common denominator has to be found. This is especially important when the water demand and supply display a strong local variability. The water balance of a region can describe water problems that water managers are faced with on a larger scale, but on a local scale this instrument has its limitations. In this paper, spatial aspects are considered in three ways: IWRM measures are compared at the river basin scale to show the options to balance water demand with supply. The conditions for the applicability of the most effective measures at the local scale are analyzed in the second step. In the last phase the allocation of such measures within the river basin under consideration of their spatial efficiency is discussed.

\section{Methodology}

\subsection{Objectively comparing IWRM measures on the river basin scale}

The recommended spatial dimension of integrated water resources management (IWRM) is the river basin. A water balance, which combines the hydrological conditions of the natural system with its man-made alterations, is a useful tool to visualize the interlinkages of the hydrological and social system and determine the extent of human interventions. It has to quantify water flows between different sources and sinks caused by water consumption of different users within, as well as in and out of the study area. Besides being a useful tool to gain insight in the hydrological functioning of the catchment basin, the water balance can clearly point out the deficits or misbalances in water fluxes. The goal of IWRM measures is to alleviate the deficits in this sector. This can achieved through a wide range of measures, as the IWRM tool palette is multifarious. However, not all measures will have the same impact on the identified deficits.

The water balance can be expanded from a static, one-time inventory of quantities and fluxes to a dynamic system, where components or elements can be changed according to predicted effects of IWRM measures. Especially if the fluxes in the water balance are based on robust hydro(geo)logical models, the standard water balance is upgraded to a dynamic meta-model. A dynamic water balance can translate the effect of water saving measures across different components. Even if IWRM measures can save large quantities of water in one component of the water system seems to be promising, their actual effect has to be assessed with regard to the limiting, or misbalanced components and fluxes of the water balance. Integrating the IWRM measures in a dynamic water balance based on an ensemble of compartments and fluxes based on interactively updatable units, allows a testing and quantifying of all measures uniformly according to their impacts on specific targets like groundwater increase/decrease.

\subsection{Specifying the feasibility of selected IWRM measures on a local scale}

Once the optimal IWRM strategy to alleviate the water stress for the specific hydrosystem in the catchment basin is determined, the next steps are to substantiate and even optimize this strategy for the sector under consideration. The first step contains an assessment of the efficiencies of different measures to improve the hydrological conditions in the basin in general, the second one the determination of their feasibility as well as the framing conditions for implementation. This means that the rough level on which different IWRM measures were compared over the entire catchment basin and across all sectors, has to be specified in more detail. Optimally both, measures selection and quantification, should be re-evaluated on a sub-basin level and compared to the overall goal. If the overall goal is still not achieved, inter-basin measures should be evaluated, starting in the upstream direction.

\subsection{Allocation of IWRM measures within a river basin}

In a third level, the spatial allocation of most effective measures has to be specified. For this purpose, the spatial distribution of hydrological characteristics and the impact of feasible water management measures have to be combined to find most efficient locations for the implementation of local measures within the river basin.

\section{Application}

\subsection{Study site}

With insufficient water resources to meet rising water consumption in northern and eastern China, over-withdrawal of both surface and groundwater is widespread (Jiang, 2009) and becoming one of the most significant limiting factors affecting sustainable development in this region (Xia et al., 2007). Shandong Peninsula, in the east of the North China Plain, is facing a particularly grim situation with an average total of only $357 \mathrm{~m}^{3}$ fresh water per capita (Wang et al., 2003), these freshwater resources are thus only $1 / 24$-th of the world average (The World Bank, 2010). Caused by high rainfall intensities, along with an expansion of agriculture, the high silt content of rivers is reducing retention basin capacity by almost 6 Mio $\mathrm{m}^{3}$ every year (Sun et al., 1998). The Huangshui river basin in Shandong (see Fig. 1) is typical for the region, with water demands exceeding the water resources in average by about $25 \%$ (Geiger, 2005), thus combining all of 


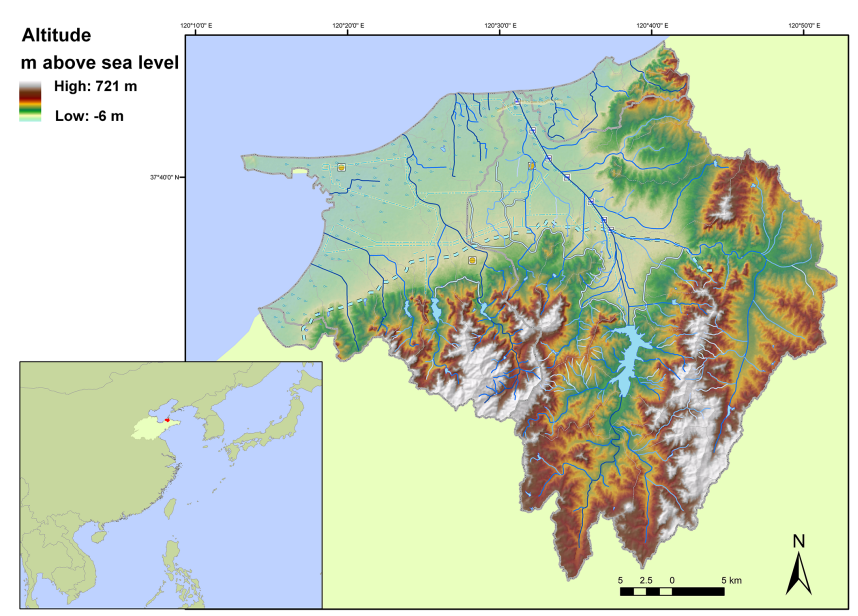

Figure 1. Location and altitude of the Huangshui river basin.

the problems that occur throughout Shandong, like groundwater depletion, dry rivers and sea water intrusion.

\subsection{Assessments of IWRM measures at the regional scale}

\subsubsection{List of IWRM Measures}

An extensive list of IWRM related management measures was collected by literature review and interviews with local and foreign IWRM experts. A water management measure was mainly defined as an approach to increase the availability of water resources compared to the current water intensity of demand and currently available supply. The details of the technical measures in the measure catalogue are compiled in an Excel workbook. Extent estimates and other calculations for many of the measures have been done on separate sheets within the same workbook. The IWRM measures were categorized in two ways; first according to water management fields or sectors, and then according to both their position in the management hierarchy as well as their effect on water management goals. More extensive Information about this catalogue can be found in Kaden and Geiger (2014).

\subsubsection{Hydrological modelling}

A water balance meta-model was set up to specify the relevance of water utilizations and their impact on the regional hydrological conditions. The three hydrological building blocks of the meta model concept consist of the simulation packages SIWA (Wirsing et al., 2010), WBalMo (Kaltofen et al., 2008), MIKE11 and FEFLOW.

SIWA is a 1-D empirical soil water model based on landuse, soil, slope and groundwater depth data. The model calculates spatially distributed monthly groundwater recharge and direct runoff rates. The input parameters for SIWA have been derived from the land-use, soil type map and groundwa- ter depth of the year 2000. In total approx. 38000 polygons with 1900 hydrotopes were generated. The average rainfall was derived for approx. 20 stations from the period 1960 2008 within the Huangshui River Basin. The evaporation could be derived from the pan-evaporation measurements made at WangWu reservoir station (Xu, 2006). Pan evaporation data were available on a monthly basis for the period 1980-2007.

To simulate the hydrological processes within the rivers and reservoirs a MIKE11 model has been set up. The software offers to simulate unsteady flow in river networks as well as looped networks using an implicit finite difference scheme. In total 25 rivers have been modeled with a total length of approx. $327 \mathrm{~km}$. Within the model 13 weirs have been integrated, among the largest is the Wangwu reservoir.

Most important input data for the vertical discretization in FEFLOW $^{\odot}$ were 17 borehole descriptions as well as 2 longitudinal profiles and a detailed geological map $(1: 50000)$. The conditions for transient calibration could be obtained from 31 groundwater observation points from the period 2000-2007. The river system was implemented as line-in elements in the mesh. The horizontal mesh consists of 34547 elements and 17651 nodes. In vertical direction 10 layers represent the geological characteristics within the model domain. The recharge could be obtained from the SIWA model. The final input parameter for the model is the extraction, both for agricultural, industrial and domestic use. Information for the years 2000-2007 was available per land use for each individual district. The main calibration period for the numerical models supporting the water balance are was 2000-2007. Two examples, which demonstrate the fit between observed and simulated water levels are shown in Fig. 2.

\subsection{Considerations of the water demand within the water balance meta-model}

A very important interface between hydrological conditions and human water use is agriculture. Falkenmark (1999) argued effectively for a broadening of the water sector's attention from the conventional "blue" water in aquifers and rivers to include also the evapotranspiration flow of "green" water stored in the unsaturated upper soil zone and involved in rain fed biomass production in agriculture, forestry, and natural vegetation systems. In the water balance of the Huangshuihe River, this demarcation of blue and green water is also integrated and visualised in blue and green colours. About $26.8 \%$ of the rainfall amount in the Huangshui-basin is converted to blue water, which is in line with global averages. The green/blue water determination has been an extremely useful illustrative concept in many situations where the role of land use in water resources management needs to be highlighted.

The input data of the meta-model water balance can be changed according to different study areas. They are categorized in three categories: 


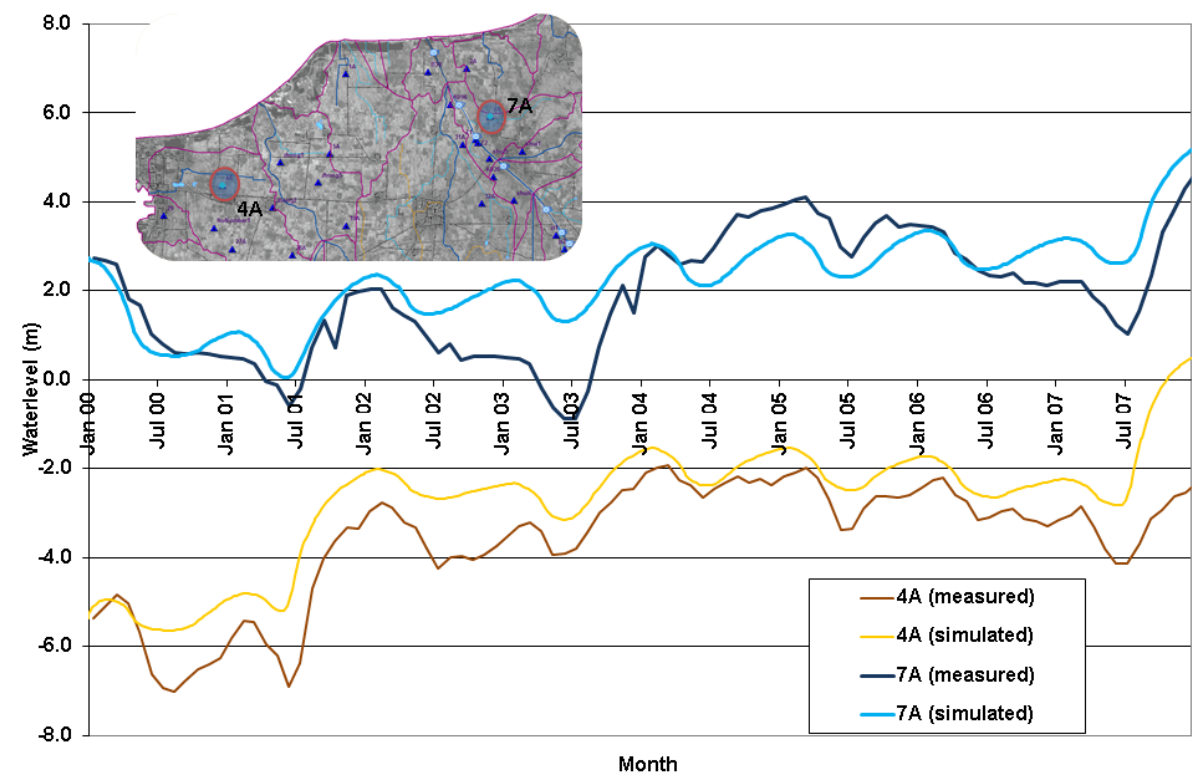

Figure 2. Measured and simulated results for two groundwater monitoring stations.

- Base parameters, like land-use categories, precipitation and PET, where mainly long-time changes are considered

- Natural balance, partitioning keys, properties of the local topography, and land-uses like runoff, percolation and outflow

- Anthropogenic balance, municipal, industrial and agricultural water needs and their respective extraction and discharge sources.

The resulting water balance is visualized as a flowchart (see Fig. 3).

Decision makers can explore the effects on the water balance of changing (decreasing, increasing) needs, proportions in the extraction sources, etc. This allows an improved understanding of water related problematic beyond each individual sector and throughout the entire water cycle. The different steering variables can be accessed through a user interface. For instance, the base parameters display the current amounts of water use, precipitation, evapotranspiration (including their increase by irrigation) and water storage. Changing e.g. the agricultural area automatically changes the related water balance factors, the supply from ground- and surface water, the transpiration and the groundwater balance. This way, rough ideas about possible trends like increases in municipal water demand, decreases in agricultural areas, etc. can be explored. Also trends in decreasing precipitation or increasing radiation can very roughly be simulated. This allows the decision maker to develop a feeling of the magnitudes and effects of, for instance, increasing surface water use in the agricultural, municipal or industrial sectors instead of groundwater use.
As can be seen from Fig. 3, the element with a yearly structural deficit of 14 million $\mathrm{m}^{3}$ year $^{-1}$ is the groundwater component. To alleviate this unbalance in the hydrosystem, the IWRM measures are to be compared according to their effects on the recharging the groundwater deficit.

\subsection{Translating the IWRM measure to a common denominator to estimate their local feasibility}

Since the interactive water balance is to "norm" the effects of the measure catalogue, the balance was opted to be programmed in the same software package, Microsoft Excel ${ }^{\odot}$. The measures were dimensioned in million $\mathrm{m}^{3}$ years ${ }^{-1}$. Measures have to be integrated in three levels. First, the measures have to be implemented. Not all measures can be implemented simultaneously, or can reach their optimum when combined with others. Each measure was attributed a Boolean operator that can be switched to active or not. Secondly, the measures have a certain impact magnitude that is estimated, as the average value between minimum and maximum. Using intervals, the amounts of water that are shifted from one or more compartments to one or more other compartments are estimated according to the implemented measure. The third level of integration is allowing the variables to vary between these respective minima and maxima and finding the optimum accordingly. A routine was written that, using the dynamic water balance algorithms evaluates all measures and their ranges individually and in combination and writes out their costs and benefits, in this case groundwater quantities. In order to explore the end results, a GUI was created that allowed de-selection of individual parameters, in/ exclusion of categories, the maximum available investment 


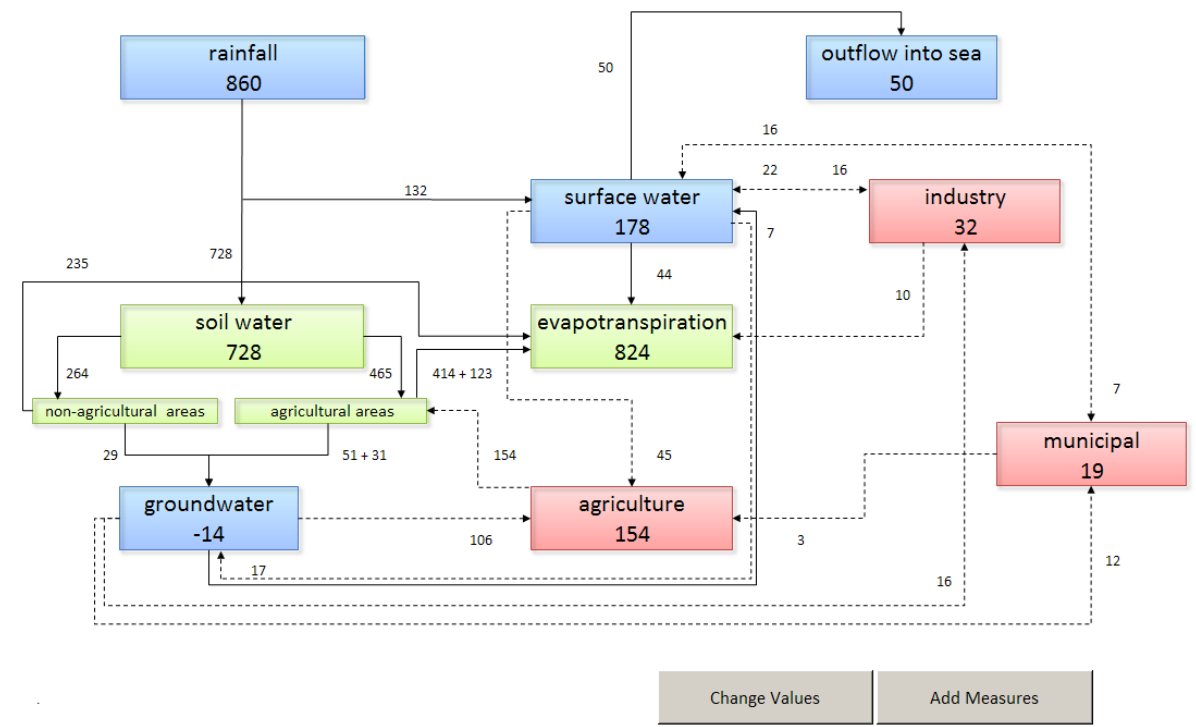

Figure 3. The water balance meta-model depicted as a flowchart with the main components and water flows.

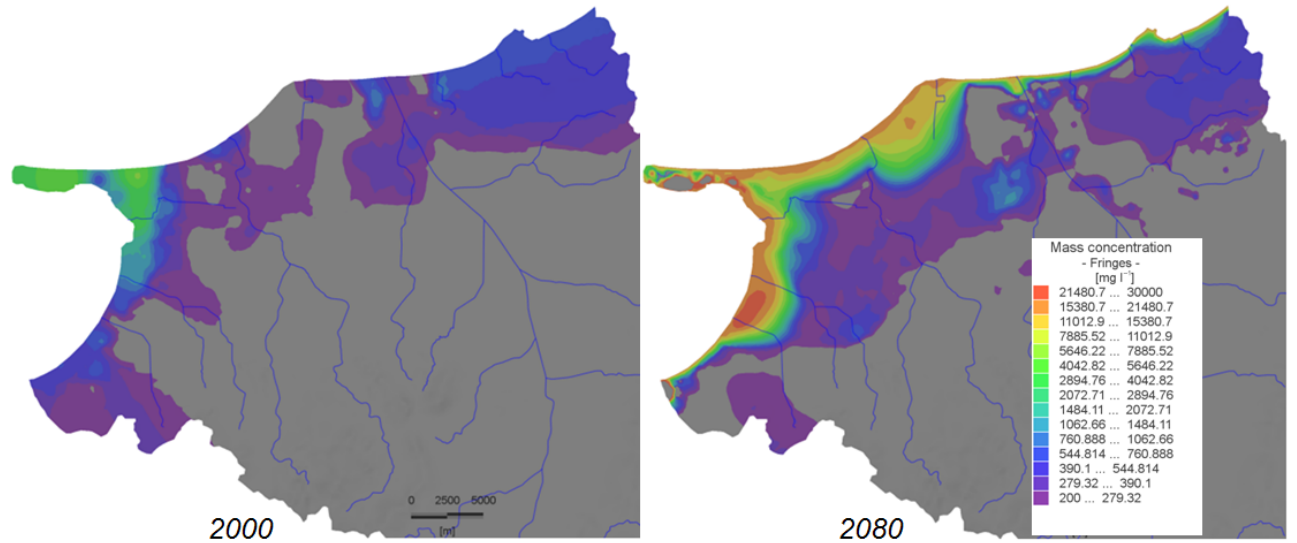

Figure 4. Saltwater intrusion at the start of simulations (year 2000) and after 80 years.

amount and the minimum required effect upon the most relevant compartment.

\subsection{Specifying the selected IWRM measure on a local scale}

After the objective selection of the optimal IWRM measure (here the reduction of the agricultural water consumption), feasible strategies to change it under consideration of socio-economic effects have to be specified. Details for this step are presented in Nijssen (2013) and Schumann and Nijssen (2014). The local dimensions and extents are to be modelled based on the recharge and run-off model (SIWA) and the water allocation model (WBalMo).

\subsection{Allocation of measures within the river basin}

As result of the previous analysis, the reduction of agricultural consumption has to be allocated to the parts of the river basin, where such measures would be most efficient. As the sea water intrusion is a creeping problem, which results from the overutilization of groundwater for irrigation and an increasing deficit of groundwater recharge, a more detailed analysis of the long-term development of groundwater conditions became necessary. To analyse the saltwater intrusion caused by the observed over-extraction, a long-term simulation was performed for about 80 years. This resulted in an alarming saltwater and groundwater level distribution at the end of the simulation (Fig. 4).

To specify feasible strategies to prevent this development, a model-based optimal allocation of the measure "reduction of the agricultural water consumption" was estimated. This 

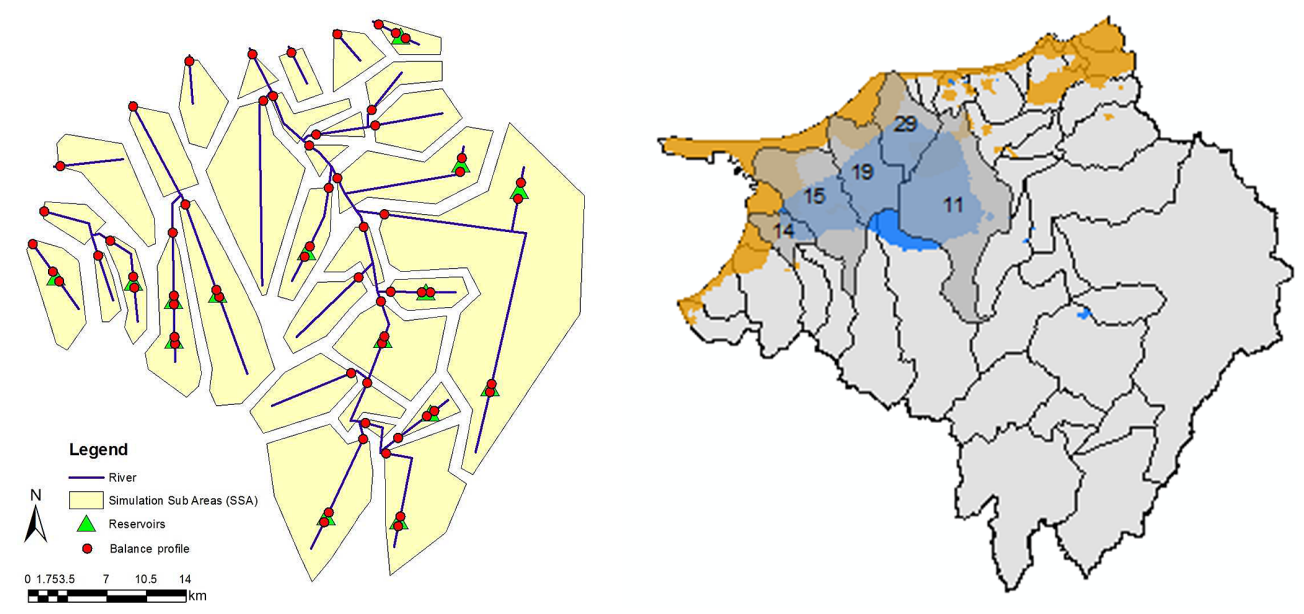

Figure 5. Left: Subdivision of the basin into water balance units, connected by river links, Right: Areas where the water extraction has to be reduced urgently (dark grey); the areas in orange show strong saltwater intrusion (mass concentration $>400 \mathrm{mg} \mathrm{L}^{-1}$, after 40 years of simulation without intervention); the areas in blue indicate a groundwater depression cone (hydraulic heads $\leq 3 \mathrm{~m}$, after 40 years of simulation without intervention).

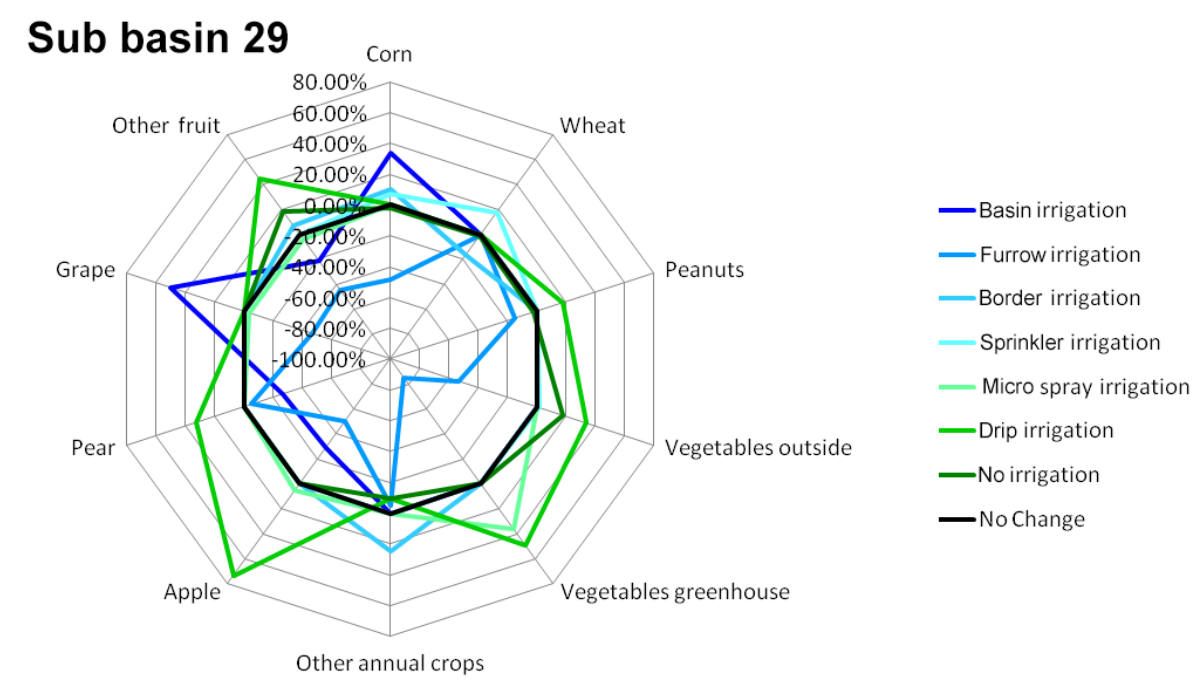

Figure 6. Proposed irrigation changes for sub basin 29, optimised to reduce the irrigation water demand whilst retaining the overall basin yield, according to local soil properties.

has to be done under consideration of the local flow conditions. For this purpose the river basin was subdivided into sub-areas (Fig. 5) which were described in their water balance by the model WBalMo. The computed groundwater recharge was the input into the model FEFLOW. Both models were used in combination to estimate the effects of with several scenarios of reductions of the agricultural water consumption with different spatial focusses. In Fig. 5 (right) the hotspot of groundwater problems, a groundwater depression cone after 40 years of simulations, is located in the subbasins $11,14,19,15,19$ and 29.

Several scenarios were simulated with the water balance model WBalMo and the groundwater model FEFLOW (Business as usual, Climate change, several agricultural de- velopments with different strategies to reduce the water demand for agriculture). Under consideration of the maximum of feasible reductions of irrigation water demand, which were estimated under point 3.4 , strategies to reduce the irrigation water demand for all hot-spot basins were derived (Fig. 6). It became evident that the stabilization of groundwater conditions could not reached by these localized measures. Thus the neighbouring upstream sub-basins were also considered. The impacts of the increase of groundwater recharge by changed agriculture upstream were analysed with the hydrological models to find feasible but effective measures. The final result of the combined model approach showed that for the Huangshui river basin, irrigation changes, crop changes, and the implementation of water pricing on top of irrigation 
changes, rank as the top three measures. Other promising measures for the local hydrological system were swale infiltration and dam construction.

\section{Summary and conclusions}

Spatial aspects are a basic problem of water management planning. Local interventions have very different regional efficiencies. Thus, the allocation of hydrological most effective local measures to improve the regional water balance is a non-trivial issue. Different steps of analyses are needed to characterize the decision space considering the hydrological effects and the socio-economic feasibility of measures. The local impacts on the water balance have to be assessed in the regional context. Efficient measures in the regional context have to be allocated in such a way, that their local feasibility is accompanied by with a regional effectivity.

\section{References}

Addams, L., Boccaletti, G., Kerlin, G., and Stuchtey, M. M.: Charting our Water Future, Economic frameworks to inform decision making, 2030 Water Resources Group, McKinsey and Company, 2009.

Bishop, C. D., Curtis, K. R., and Kim, M.-K.: Conserving water in arid regions: Exploring the economic feasibility of alternative crops, J. Agr. Syst., 103, 535-542, 2010.

Bjornlund, H.: Incentives and Instruments for Sustainable Irrigation, WIT Transactions on State-of-the-art in Science and Engineering 37, 240 pp., ISBN: 978-1-84564-406-2, 2009.

Brouwer, C.: Irrigation Water Management: Irrigation Methods, Irrigation water management: training manuals 6 , FAO, Rome, 2005

Cai, X.: Water stress, water transfer and social equity in Northern China-Implications for policy reforms, J. Environ. Manage., 87, 14-25, 2008.

El-Dessouky, H. T. and Ettouney, H. E.: Fundamentals of Salt Water Desalination, Elsevier Science B.V., 2002.

Falkenmark, M.: Forward to the future: a conceptual framework for water dependence, AMBIO, 28, 356-361, 1999.

Geiger, W. F.: Cost-effective measures for flood control and groundwater recharge in coastal catchments. Research Project Founded by BMBF, Förderkennzeichen: CHN 04/015, Bonn, 2005.

Ghassemi, F. and White, I.: Inter-Basin Water Transfer, Case Studies from Australia, United States, Canada, China and India, Cambridge University Press, 2007.
Governing Board of the National Research Council: Water Conservation, Reuse and Recycling Proceedings of an Iranian-American Workshop, Inter-academy workshop on water resources management, conservation, and recycling, Tunis, 2005.

Jiang, Y.: China's water scarcity, J. Environ. Manage., 90, 31853196, 2009.

Kaltofen, M., Koch, H., and Schramm, M.: Water management strategies in the Spree region upstream of Berlin, in: Integrated Analysis of the impacts of Global Change on Envronment and Society in the Elbe basin, edited by: Wechsung, F., Kaden, S., Behrendt, H., and Klöcking, B., Weißensee Verlag, Berlin, ISBN: 978-3-89998-145-2, 2008.

Kaden, S. and Geiger, W. (Eds.): Overall-effective measures for sustainable water resources management in the coastal area of Shandong Province, PR China, Concepts for Sustainable River Landscape Development, Vol. 10, 346 pp., ISBN: 978-3-89998-212-1, 2014.

National Development and Reform Commission (NDRC): China Water Conservation Technology Policy Outline, Announcement No. 17, 2005.

Nijssen, D.: Improving Spatiality in Decision Making for River Basin Management, Schriftenreihe Hydrologie - Wasserwirtschaft 27, RUB, Ruhr-Universität Bochum, 147 pp., 2013.

Patel, A. S. and Sah, D. L.: Water Management - Conservation, Harvesting and Artificial Recharge, New Age Int., New Delhi, 2008.

Schumann, A. and Nijssen, D.: Shortage and surplus of water in the socio-hydrological context, Proc. IAHS, 364, 292-298, doi:10.5194/piahs-364-292-2014, 2014.

Sun, Z., Song, C., Pang, H., and Li, W.: Eco-restoration engineering and techniques in the Muyu reservoir watershed in Shandong, P.R. of China. Ecol. Eng., 11, 209-219, 1998.

The World Bank: Development and Climate Change, World Development Report, Washington, ISBN: 978-0-8213-7987-5, 2010.

Xia, J., Zhang, L., Liu, C., and Yu, J.: Towards better water security in North China, Water Resour. Manag., 21, 233-247, doi:10.1007/s11269-006-9051-1, 2007.

$\mathrm{Xu}, \mathrm{Ch} .-\mathrm{Y}$.: Analysis of spatial distribution and temporal trend of reference evapotranspiration and pan evaporation in Changjiang (Yangtze River) catchment, J. Hydr., 327, 81-93, 2006.

Wang, Y., Zhang, Y., and Zheng, W.: Water resources and potential of seawater desalination in Shandong peninsula, Desalination, 157, 269-276, 2003.

Wirsing, T., Deinlein, W., Hofmann, B., Maier, M., and Roth, K.: Modellierung des Bodenwasserhaushalts als PrognoseInstrument zur praxisnahen Abschätzung der Umweltauswirkungen einer Grundwasserabsenkung, Hydrogeologie, Fachberichte, gwf-Wasser|Abwasser, 2010. 